\title{
A Corpus-Based Discourse Analysis Study of WhatsApp Messenger's Semantic Notifications
}

\author{
Nisreen Al-Khawaldeh \\ Department of English Language and Literature, The Hashemite University, Jordan \\ E-mail: nal-khawaldeh@hu.edu.jo \\ Baker Bani-Khair (Corresponding author) \\ Department of English Language and Literature, The Hashemite University, Jordan \\ E-mail: bakribakr@yahoo.com \\ Bassil Mashaqba \\ Department of English Language and Literature, The Hashemite University, Jordan \\ E-mail: b_mashaqba@hu.edu.jo \\ Anas Huneety \\ Department of English Language and Literature, The Hashemite University, Jordan \\ E-mail: AnasI@hu.edu.jo
}

Received: 05-06-2016

Published: 01-11-2016
Accepted: 11-08-2016

doi:10.7575/aiac.ijalel.v.5n.6p. 158
Advance Access Published: September 2016

URL: http://dx.doi.org/10.7575/aiac.ijalel.v.5n.6p.158

\begin{abstract}
This study is the first to analyse WhatsApp's semantic notifications particularly those of Jordanians. It also seeks to analyse the differences in these notifications' language use by gender and endeavors to reveal some latent socio-cultural values affecting the way users make certain language choices in these online notifications. The study contributes to knowledge since such analysis helps to reveal unique networks of individuals communicating through Arabic and English in unique and innovative ways. It mainly assists in describing the members of the Jordanian society revealing a great deal of information about their personal status, their activities, society and problems. The discourse analysis of these notifications also describes how the language has been adjusted to online discourse. The written status notifications from 300 WhatsApp's users were compiled and analysed based on a critical discourse analysis to form a predictive model of the users based on their language and to investigate the traces of social values in these semantic expressions and explain their connotations and functions in discourse. Results indicated that the language used in WhatsApp's status notifications were a mixture of both standard and non-standard abbreviations, reduced endings which were ungrammatical. It was also found that the linguistic notifications-based assessments constitute a valid reflection of the status of its users and their society as a whole. They were as a revelation of personal, social, religious and political issues the users are concerned about. Differences with respect to gender were not found in structural construction of the language rather in categories indicating various themes. Results showed that females status updates are more personal, religious and social while males are concerned more about political, national and international themes.
\end{abstract}

Keywords: Linguistic feature, WhatsApp's notification status, critical discourse analysis, socio-cultural features, language variation and corpus

\section{Introduction}

The evolution of computer-mediated communication (CMC), a text-based communication between human beings via internet networked computers, is considered a substantial change in human communication (Cvjecovic, 2010, Unuabonah, 2010 and Him, 2012). The language variety that largely typifies online writing is coined by (Crystal, 2006) as textese. WhatsApp has become one of the world's largest social network sites (i.e. Facebook, YouTube, Twitter etc.) used in the world (Ahad and Lim, 2014). The rapid spread of instantaneous mobile messaging applications like WhatsApp has its impact on generating special linguistic features archetypal for this type of computer mediated discourse (CMD). Since 2009, WhatsApp, a mobile instantaneous interne-based messaging application, has been used by millions of users worldwide, exchanging messages, sharing photos and making calls (Acton and Koum, 2014; Ahad, and Lim,2014). People express themselves by writing in WhatsApp's notification status. Through these written texts, users openly share their thoughts and emotions with their friends, colleagues and acquaintances. Language use in such social network sites can be viewed as a reliable psychologically and socially rich individual difference self-report (Adali 
and Golbeck, 2014; Park et al., 2015). This could support others' studies' finding of a firm evidence linking language use to personality (Tausczik and Pennebaker, 2010; Yarkoni, 2010; Schwartz et al., 2013). According to Castells (2007), the information people share via the web is "self-generated in content, self-directed in emission and selfselected in reception" (248). Therefore, such written discourses can be regarded as an immense source of rich psychological data. Scrutinizing them could result in a great revelation about the underlined personal, social and political issues.

\section{Literature review}

Research suggests that any communication given over phone, email, or instant message carries a share of the total discourse on a particular topic [16]. The word 'discourse' is the main idea that people's language that is structured according to in various domains of life such as social discourse, or political discourse. From a pragmatic point of view, the message conveyed by a text can be realised by speech act which consists of Locution (i.e. the actual meaningful linguistic expression and its ostensible meaning); Illocution (i.e. the intended meaning of the given utterance) and Perlocution (i.e. the actual effect of that given utterance upon feelings, beliefs, or actions. such as convincing, or inspiring) (Austin, 1962). This applies to WhatsApp's notification in that communicators leave certain texts with the intention to convey a message that provides information on their current whereabouts that leaves an effect on the receiver. Users try to leave powerful texts in order to put certain political, economic and social ideas into practice.

Language plays a crucial role in human being society as it eases the transmission of knowledge and ideas (Maynard and Peräkylä, 2006; Krauss, and Chiu, 2007). Therefore, Pennebaker and Graybeal (2001) argue that language structure used can be viewed as a designation of publics' psychological, cognitive, and social physiognomies. Variation of language can be seen in use of factual or content (e.g. topical themes concerning domain such as work, study, home), emotional (e.g. Words signaling negative and positive emotions towards something) or functional words (e.g. pronouns, auxiliary verbs articles, conjunctions and negations) (Pennebaker, Mehl, and Niederhoffer, 2003; Kahn, et.al., 2013). Each type of words signifies certain meaning; second person pronouns imply social engagement compared to first person pronouns which signify self-focus.

The analysis framework adopted for this study consists of both textual analysis and critical discourse analysis. In light of Van Dijk (2001), textual analysis can be done on both micro aspects concerning linguistic choices (i.e. lexicogrammatical choices) and macro-aspects concerning 'global meanings' (i.e. schematic representations). Identifying both the macro- and micro-features of language used in notifying about the status can form a base for analyzing the power relation and the socio-cultural factors immersed in the Jordanian society. In this respect comes critical discourse analysis Fairclough (1995). The analysis of our data is grounded in Fairclough's conventions in critical discourse analysis, arguing that "ideologies reside in texts" that "it is not possible to 'read off' ideologies from texts" and that "texts are open to diverse interpretations" (Fairclough, ibid). Fairclough (ibid), argues that discourse duplicates and reflects social beliefs and structure. Critical discourse analysis besides mirroring and reflecting what goes on in society, it endeavors to interpret relationships amongst people and clarify how social power is ratified and legitimised by a specific leading entity. In other words, it examines that opaque reciprocal interplay and relationships amongst people's texts, events and practices and broader social and cultural structures and relations to consider how these texts, events and practices arise out of and are ideologically formed by relations of power. That is why Van Dijk (2003) believes that discourses are intrinsically part of, and impacted by social structure, and shaped in social interaction.

\section{Statement of the problem}

It is widely noticeable that people have been leaving Facebook recently and migrating to newer social media platforms such as WhatsApp and Snapchat, which are found "cooler" (Kiss, 2013). According to Parate and Tripathi (2015), WhatsApp reigns supreme among mobile chat apps. The overuse of a special form of language for text messaging is notable among youths which has rather extended to be used in other types of pieces of writing (Salem, 2013). Social media has significantly influenced the social and cultural textile of our society by revolutionizing the way people communicate and socialise (Salem, 2013; Al-Sharqi, et.al. 2015). Despite, the positive and prominent role instant text messaging plays in socializing and sharing information (Sweeny, 2011), researchers claim that it has an adverse influence on language proficiency particularly spelling and grammar skills (Mphahlele and Mashamite, 2005; Rankin, 2010; Salem, 2013). This is because it causes people to forget the correct forms of English language which eventually results in a deviation from the Standard English Language taught in educational institutions.

Compared to other fields, research on online social networking language usage is still in its infancy (Stidham, 2014). Research on WhatsApp has mainly focused on its influence on students learning process (Amry, 2014). This is all invaluable research and the present study contributes to the already existing research. Written social media language is of a great significance to be studied since it captures interactions among friends and acquaintances that are obviously an essential part of their lives through which they disclose a great amount of personal information that can be retroactively accessed for research purposes (Naaman, Boase, and Lai,2010). In addition, as Back et al. (2010) argue that social media language normally presents people's true selves rather than their idealised ones. Therefore, they can be used as a barometer, a way of measuring the influence of people's changes of life on their language. Besides, they can be considered hypothetically a very rich spring of personal, social and political data to be scrutinised. As Farzindar and Inkpen, (2015) claim, the semantic analysis of social media's data is defined as the linguistic processing of notifications and messages that are enriched with semantics and meta-data and exchanged over the social media networks. Compared to the data available on some social media sites such as Facebook and Twitter, there is a scarcity of research using critical discourse analysis (CDA) as an explanatory or analytical framework for exploring online data particularly 
language use in WhatsApp's status notifications. There are gender differences in teens' internet use (Herring and Kapidzic, 2015); however, how genders represent themselves to others through online social media still needs further explanation. Reviewing the previous literature reveals a dearth of research about socio-linguistic aspects of the WhatsApp as well as the impact of gender on the language used in online social sites. To the best of the researchers' knowledge, there has been no study conducted on analyzing WhatsApp's semantic notifications and the impact of gender on them. Thus, this study was conducted to analyse the expressions used in WhatsApp's status notifications to fill the gap in research.

In addition, though some corpus linguistic research tackles multilingualism, the field is dominated by corpora of moreor-less distinct languages such as English, French and Spanish. Thus, Seidlhofer (2011) calls for a more multilingual or "superdiverse" datasets. Besides, Baker (2012) claims that the field of corpus linguistics has not yet adopted or applied concept of superdiversity, notwithstanding its association with the growing literature on sociolinguistics. This implies that there is a need for such a present study which adds to the corpora of Arabic and English.

\section{Importance of the Study}

The paper is hoped to be a step further towards casting light on the impact of the widespread of improvements noticeable in the fields of communication technology on Jordanian people's ways of communicating their thoughts, believes and customs as well as on their English language use. Thus, it makes a unique contribution in imagining what constitutes the language of the Jordanian community in the networked society and what its reflections are. The study contributes to knowledge through normalizing and generalizing the language employed to express WhatsApp's users' status notification by considering their peculiarities and adapting the features used to their structure and content. It identifies and discusses the morpho-syntactic features of the language of WhatsApp's status notification and examines whether the morpho-syntactic patterns used and the main ideas expressed by Jordanian youths in WhatsApp's status notifications differ according to gender. Thus, it is expected that the study will provide insights into the understanding of the language of WhatsApp's notifications and the ways through which WhatsApp's users manipulate the conventional or morpho-syntactic patterns used in order to suit their own specific purposes. Studying language variations in WhatsApp's status notification could make a tangible contribution to the field of language and computermediated communication. In addition, the study will give insights into the effects of social networking on the language use. Considering the abovementioned research gaps, the study is expected to be a good enrichment to the existing literature. Ultimately, it is expected that the study triggers further researches tackling the impact of novel technologies on English language and people's ways of presenting themselves.

\section{Methodology}

\subsection{Research questions}

What are the key characteristics of the language used in WhatsApp's semantic notifications?

What purposes do WhatsApp's semantic notifications serve?

Is there gender difference in WhatsApp's semantic notifications?

5.2 Research design and instruments

This is a qualitative corpus-based study. Discourses drawn from social media sites are suitable for corpus linguistic studies as they are digital, abundant and natural. Social media is a constant experiential sampling method (Naaman, Boase, and Lai, 2010). Two hundred status notification texts were collected only from the WhatsApp of the volunteer users. They were analysed linguistically and thematically. The length of each text for the data was between one sign, letter, and a word to excessive usage of short texts. The corpus of the study has been collected by the author in 2016.The participants voluntarily participated and contacted their contacts. Concerning ethical issues, upon knowing the aim of the study, all the participants agreed on my use of their WhatsApp's' notification status. The data were morphosyntactically and thematically analysed. The status notification messages were analysed into simpler language features: words (e.g. love), phrases (e.g., happy birthday)., and sentences (e.g. I am proud of you); non-word features such as emoticons (e.g.,:), punctuation (e.g.,?????), and nonconventional spellings and acronyms (e.g., omg!, lol) and classified according to specific themes or topics (social, political religious and personal (i.e. emotional and psychological) in light of gender. After examining the macro- and micro-features of WhatsApp's notifications, clarifications of the linguistic choices along with some socio-cultural values in Jordanian society are given. The findings were then analysed in light of the related studies highlighting the similarities and differences between the present and previous findings.

\section{Results and Discussion}

This section presents and discusses the results of each question as follows:

\subsection{What are the key characteristics of the language used in WhatsApp's semantic notifications?}

The analysis of the WhatsApp's corpus data reveals valuable data about the motivational drive behind writing certain notification more than using the already designed ones (e.g. I am at work, available, WhatsApp's messages only I am using WhatsApp). It was found that WhatsApp's users use status to generate and preserve a detailed personal profile reflections and representations for others in their social network to view. They were a way of expressing oneself and personal believes and documentation of certain group membership (i.e. mums, family, workers, nation, and team). Investigating these written discourses in a way or another examines what is going in the mind of the individual about their life and community and helps look for patterns between all users to find a common denominator. This finding is consistent with Bauman's (2006:238) view of online sites as “an ongoing narrative of the self” and Liu's (2008) view of 
them as the scene for 'taste performances' that describe and distinguish social identity as well as Sweeny's (2011) finding that instant text messaging plays a vital role in exchanging information, socializing, and structure communication. This finding coincides with (Kapidzic and Herring, 2014) that such status notification is like a profile that constitutes invitations to social interaction and encourages truthfulness. These notifications are an essential feature of mobile phones as they update users about a diversity of other people, events and cases, upon which users may take immediate action or ignore them depending on their significance and their present context. Such notifications are a type of discourse that defines people and their culture. Such notifications can be viewed as a set of values, thought and beliefs that enlightens about social responses and actions. This explanation matches Burr's (2003) claim that analysis discourse is essential because it takes into account both language and interaction in constructing social norms.

The analysis also revealed the simplicity of the language used in the status nonfiction in terms of structure. The majority of the notifications were either written in Arabic or English or both. This could reveal the extent to which English has dominantly influenced Jordanians' use of Arabic. Despite the fact that the vast majority of the participants were not English learners, they managed to code switch between Arabic and English perfectly. The language of these notifications could be characterised having one letter "N", abbreviations with special expressions "omg!"), repeated punctuation signs such as "multi-fullstops, multi-exclamation and multi-question marks" many sentences " my mum in my heart. I love you a lot. Without you, I will be lost". The notifications were in form of both verbal (using letters) and non-verbal (using emotional pictures(-), small, upper case and a mixture of both as well as a mixture of both standard (formal) and non-standard language (informal). The emoticons signs were used the participants to replace using mood and attitudes-related words such as "positive", negative" and "neutral". The formal and informal language were analysed; the standard language was exhibited in a poetic verse, Quranic verse“Say, "He is Allah, the One", prophetic saying "One who covers up the failings of someone in this world will have his shortcomings covered up by God on the Day of Judgment", and a proverb "People who live in glass houses should not throw stones" .Another feature generally observed in the corpus was the usage of specific textual means to substitute standard language. The use of non-standard language were exhibited by certain linguistic features employing a slang language (i.e. informal language with particular expressions such as "lol” (laugh), "OMG” (Oh! my God), "gd” (good), plz (please), "Urggghhhhhh!! V Stud mate", "ysdefo!, oh v tired, wannasleeeep), emotional signs besides non-standard use of grammar by over extension of letter (i.e. repeating some of letters in a word" to emphasise words. The repeated lettered word "perrrrrrrfeeeeect timing" and "veeeeeeerrrrrytirrrrrrrrreeeed, 'riggggghhht', its ur turn now" rather than "perfect timing", "very tired", "right, it's your turn nowwww" can be seen as a way of stressing the words and its effect on the reviewers. Writing such words in a way they would be pronounced if it were spoken indicates informality. For example, the use of "lol" shows that the user indirectly expresses feelings to another user in his/her contact revealing understanding of each other informally. Using informal language It may be viewed as a form of revealing unique identity, triggering the sense of joy and irony, signaling solidarity, or resistance to complying with norms or rules imposed on the participants. They mainly come in weird spelling "fone instead of phone", as well as letter and number homophones ("gr8 luv 4u" instead of "great love for you"). Such features of the WhatsApp's notifications' language could be ascribed to the fact that people write their words the same way they pronounce them. This implies that the language used in WhatsApp's status notification is simplified, fragmented, abbreviated shortened and conditioned to fit the context of online communication. This finding coincides with Crystal (2006) that that the language in Internet communication is a variety of the conventional one. The finding also lends support to Salem's (2013) finding that the instant and text messaging comprises of non-standard abbreviations, verb omission, and reduced endings which are ungrammatical. This finding matches Thurlow's (2003) classifications of text messages as non-standard typographic or orthographic forms such as excluding g as in "Goin" (going), deletion of end letters except the final letter as in "After" (Aft), deleting the middle letters as in Nxt (Next), forming acronyms from initial letters as in "LOL" (laugh out loud), forming acronyms from letters and numbers as in "b4" (Before), using letter homophones as in "U" (you), and ill-spelled words as "Nite" (night). In addition to Thurlow's (2003) classifications, Thelwall (2009) adds accent stylization as found in the present study, for example "wanna" instead of "want to "and "gonna" instead of "going to" which is often used humorously. These findings are consistent Mphahlele and Mashamites' (2005) and Thurlow's (2006) outcome that short messages language influences language proficiency of learners on the short and long term particularly their skills of expressing themselves persuasively besides the skills of using words appropriately according to context. Though such forms of language are the most generally used ones, the result is in line with Taglimonte and Denis (2008) who envisages that people use standard language in text messaging for specific purposes in some contexts.

\subsection{What purposes do WhatsApp's semantic notifications serve?}

The analysis of the data revealed that the majority of the participants shared histories, interests, norms and customs, and self-awareness that their groups were close. The WhatsApps' notifications have been viewed as a great way of revelation communication to a group rather than one-one basis since these status updates generally are not directed to a specific audience. They are fascinating as in them people can touch on everything from personal, social to political concerns directly or indirectly. Percentages of the recurrence of the themes are demonstrated in Figure 1 and an interpretation of the influence of socio-cultural aspects on the production of those status notification discourses is provided. 


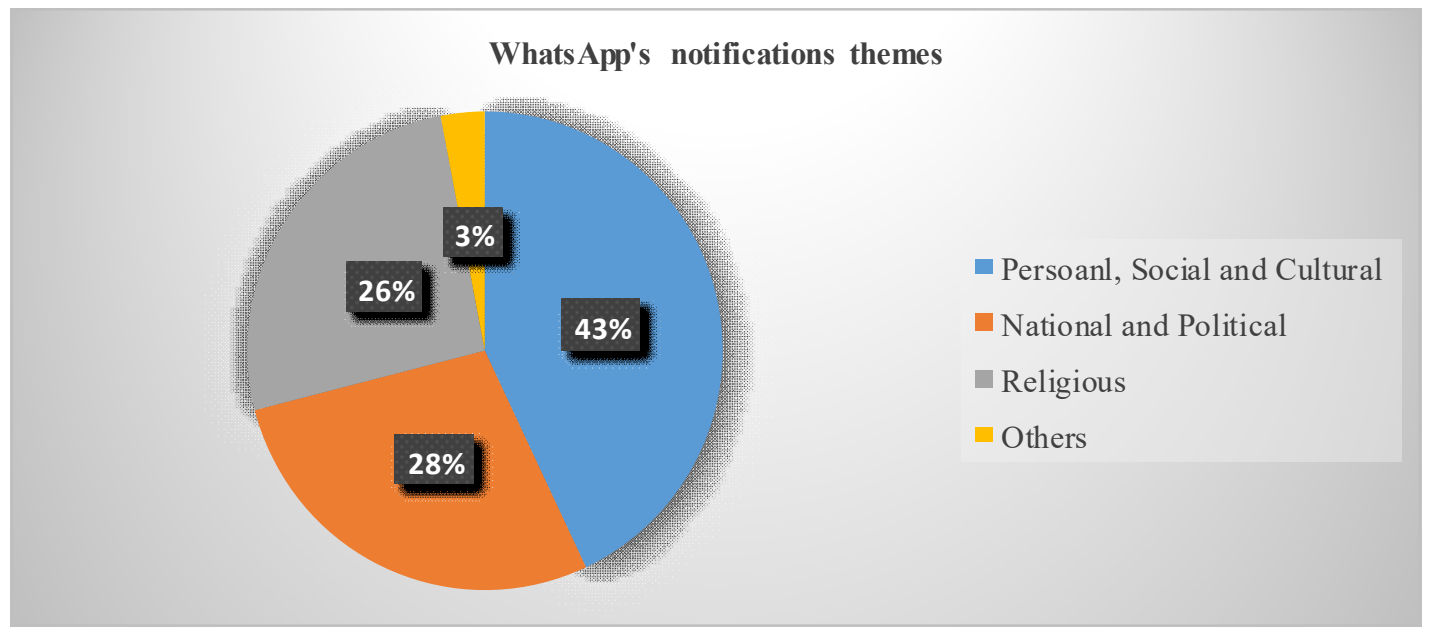

Figure 1. The most common WhatsApp's notifications

The main themes found to be notified about could be classified as follows:

1. Personal, cultural and social themes: The language used in WhatsApp's status updates are seen as a representation of a particular personality, community, and ethnic or national group. They provide invaluable data that reflect the collective everyday life, social problems, values, rituals and feelings of the individuals of that particular culture. However, it should be noted that these discourses can be taken as representing a significant portion of the target community, rather than just the attitudes of particular person. The personal themes can be classified into the sub-categories:

- Emotional: "I am fond of you", you are my love", "Ruba is at my heart", "Dear Mustafa, you are my source of Happiness", "I promise you, darling, we will not be apart", "I love you close to infinity", "you are the twin of my soul", "I love you MUM", "your eyes are a novel and I love reading", " the best love is the kind that awakens the soul, ad makes us reach for more, and plant a fair in our heart". " if I were his daughter, I would envy his daughter for having him"

- Health: "I am very sick", “Alhamdulillah, I went through a successful small operation”, "my health can no longer bear it"

- Birth: "Congrats! A new baby boy", a pretty baby girl has arrived"

- Wedding and engagement: "It is my pleasure to invite to my wedding party on Thursday at 8:00 pm in Celebrations Halls, Amman, Al-Jubaiha

- Graduations and promotions: "Graduation Time ", "Wishing you, my DAD all the best with your new promotion".

2. Religious themes: people benefit from these slots to reveal, reiterate and strength their religious faith and pious believes. These linguistic expressions come mainly in the form of Quranic verse "Say, 'He is Allah, the One; Allah, the Independent and Besought of all. He begets not, nor is He begotten; And there is none like unto Him", " those fear Allah, will find their way out of troubles" , "with hardship, always comes ease"; supplications and prayers "May Allah protect you all” , " may Allah endow me peace of mind”, " may Allah always remind me to recite his name", " Oh Allah, I ask you present much better than I wish and future greater than I dream, and life smoother than I want", "Alhamdulillah for everything forever" ; "Only God can change people from Zero to Hero, so keep praying and remember Allah is always with you", "if you belief that Allah is the Almighty, you will be not care too much for mundane things", "May Allah give you Ayoub's patience, Suleiman's wealth, Yousef purity, Mohammad's morals, oh Allah give us a drop from their sea". There are expressions in a form of reminding people of carrying out religious duties such as " if awaking to pray Fajir was not the first priority and decision to make every day, your life is worthy nothing", " only when you prostate. For God, tell God what is in your heart, this time you will sleep quietly", "feed your faith and your doubts will starve to death". " be patient, God will give you until you are satisfied". "Do not be depressed, do not feel worries, Allah is the One."

3. National and political themes: the WhatsApp's users avail the status notification to reveal some political concerns: they either disclose their national unity using mottos (e.g. " Allah, The Home county, The King" "Jordan is First", "I miss my home country, JORDAN", " my heart beats Jordan”), social and national songs and poems " The king live longer"," Jordan is my country"; sport slogan "Alfaisaly Alzaaeem(i.e. Alfaisaly (the Jordan's national team is the leader" , "Alwihdat only ( a Palestinian football team " Hello Madrid"; Certain expressions to show their feeling of resentment of the status-quo of some surrounding countries "e.g. "The Arabic spring!" and Aleppo is burning", "who is in Jerusalem?" or the world "”....... It can be argued that users find themselves freer to divulge their political concerns since they are not under the influence of the physical presence of specific intimidating social presence or the voices of superior parties 
rather they are sharing their disclosure with very close people they chose to be in their contacts. Some other expressions are merely news such as "Queen Rania visits the home of the martyr Rashid Al-Izyoud"

4. Others: certain status discourses are ambiguous, thus they are open to different interpretations such as "May the thing that perplex you cause you to be alert", "There are many things that make you live longer", "justifications from behind masks will not convincing", "It is intentional", " some people are like history they can't come back and they are not forgettable". "I want to talk about optimism COS inside me there is a home country of wishes". These statements match something and or reflect something insider the writer. In addition, there are other statements without any of the story behind them can be viewed as only a purposeful way to entertain the reader such as humor " e.g. life taught me many things but I have learned nothing", " they say the certificate is like a weapon, have ever seen a certificate shooting anyone'."Humor is considered a fundamental part of the discoursal practices of Jordanian community including the use of including self-mockery, banter, and teasing. Besides expressing solidarity and strengthening the familiarity and friendship between people rather than distance and antipathy, such playful use of language (i.e. humor expressions) are found to serve actual societal functions lessening power imbalances; licensing challenges to status hierarchies; forming common ground; marking in-group boundaries(Boxer \& Cortes-Conde 1997; Kotthoff 1996). Other expressions are in a form of advice and wise as well as educating expressions such as "Always appreciate what you have before you are made appreciate what you had", "you can't change the past so focus on making a great future", "Worry can't stop the pain of tomorrow but it steals the joy of today", "always be optimistic and smile to be able to live", "knowledge builds houses with no ....stilts", "work hard in silence, let success make the noise", "your dream does not have an expiration date, take a deep breath and try again", "stay strong for yourself", " no one knows the tiny moments when your soul died and no one knows why you smile when you are alone, thus be strong for you", "the hardest battle is when other people enforce you to be a different person", " the smile is taking a small place from your face but it takes a big place in hearts of others" " drink water much more at daytime and less at night", "shyness is not only for men, if some men were shy, their maleness increases and their well-bringing appears and women's madness of them increases", " do not take a nap after taking a medicine immediately", "stay hungry stay stylish', "do not drink medicine with very cold water", "we are not enforced to justify our situations coz those who know us very well understand us very well", " winners never quit and quitters never win". Due to the strong communal relationship, Jordanians are well-known for their preference to exchange wisdom and advices. There are some expressions which are produced and formulated as type of monologue such as "my dream....I will do my best to make you come true wait and watch me", "I am very brave; I will ultimately achieve it", "I have to be always proud of myself wise with others and a source of happiness to myself and others", "judge yourself". These expressions serves as a personal reminder which keeps prompting their writers, "I trust myself, I live a king", "life has no remote control, I have to get up and change it myself'.

The analysis of the data gives some insights into more general socio-cultural aspects of the Jordanian society. Investigating these elements of the Jordanian socio-cultural context would be beneficial in providing a descriptive account of influence of society on language and how the certain concepts such as power (i.e. domination and authority)technically works and is conveyed the language used. This point is very relevant to Van Dijk's (1998a: 6) view that 'if we want to know what ideologies actually look like, how they work, and how they are created, changed and reproduced, we need to look closely at their discursive manifestations'. This is because what WhatsApp's users write is in some way influenced by their way of thinking and their perceptions of the world. Therefore, such written the notifications have access to and reflect what is going in users' minds, sense of reality and their understanding of the world. This indicates that WhatsApp's status notifications could also be viewed as a tool for transmitting values, norms, experiences and believes that make specific person or society unique. Thus, they serve as an aid for real-time sharing of information.

\subsection{Is there gender difference in WhatsApp's semantic notifications?}

The WhatsApp's notifications were then analysed qualitatively with respect to gender. It could be argued that both genders used the same formulae structures being explained earlier in a more homogenous way than initially anticipated. Both corpora were characterised by the use of a non-conventional use of abbreviations, punctuation, and spelling. Despite the similarities of the structural constructions of the expressions being used, the inspection of the WhatsApp's status discourses reveals that male and female vary in their main theme in focus (i.e. differ in two major respects). Unlike the tendency to focus on religious and romantic themes in their conversations, males seem to be eager highlight their interest in political and social issues. Females status updates generally contain more immediacy words than males. This finding lends support to (Lenhart, 2012; Herring and Kapidzic, 2015) that there are gender differences in teens' internet use.

\section{Conclusion and Recommendations}

The present research found languages in WhatsApp's notifications are greatly harnessed and correlated to create a valid and reliable measure of its users 'personality and status. The data highlighted the great atrocious influence of using various informal language varieties on their language proficiency both in Arabic and English with respect to spelling. It could be argued that using these erroneous shortcuts might fossilize on the long term, thus they cannot be fixed easily through practice. Considering the fact that WhatsApp could be integrated into the EFL classroom through a multi-user group, it is expected that using such online language varieties might lead to detrimental effects on students' learning of 
the standard variety of the native and EFL languages. The study highlighted the impact of using English rather than Arabic by Jordanians to express themselves on the long term. Thus, the present researchers support Salem's (2013) suggestions that linguists should find a way to standardize the use of these erroneous shortcuts as this will be of great help for non-native speakers of English.

Although conventionally online social networking is depicted as being mainly teenager's world (i.e. digital natives) (Prensky, 2001), the number of adults and seniors using it has recently grown immensely (Duggan and Smith, 2013). Thus, a study should be conducted to examine if different age groups use language differently on these online social networking sites particularly status notification. Further research is needed to examine the like Facebook's status updates and posts to enrich computer-mediated discourse research. A quantitative study is needed to collect information from different communities about language variation usage in light the social background of WhatsApp's users including age, education, profession, and motive for communication.

\section{References}

Adali, S., andGolbeck, J. (2014). Predicting personality with social behavior: A comparative study. Social Network Analysis and Mining, 4, 159.http://dx.doi.org/10.1007/s13278-014-0159-7.

Ahada, A. and Lim, S. (2014). Convenience or Nuisance?: The 'WhatsApp' Dilemma. Procedia - Social and Behavioral Sciences 155, 189-196.

Al-Sharqi, L., Hashim, K. Kutbi, I. (2015).Perceptions of Social Media Impact on Students' Social Behavior: A Comparison between Arts and Science Students. International Journal of Education and Social Science, 2(4), $122-131$.

Amry, A. B. (2014). The impact of WhatsApp mobile social learning on the achievement and attitudes of female students compared with face to face learning in the classroom. European Scientific Journal, 10(22), 116-136.

Baker, P. (2012) 'Acceptable bias?: Using corpus linguistics methods with critical discourse analysis.' Critical Discourse Studies 9(3), 247-256.

Bauman, Z. (2013). Consuming life. John Wiley \& Sons.

Burr, V. (2003). Social Constructionism, Routledge.

Chung, C.K., Pennebaker, J.W. (2013) Counting little words in big data: The psychology of communities, cultures, and history. In: László, J., Forgas, J., Vincze, O. (eds.) Social Cognition and Communication. Psychology Press, New York.

Crystal, D. (2006). Language and the Internet. Cambridge: Cambridge University Press.

Farzindar, A. and Inkpen D. (2015). Natural Language Processing for Social Media. Morgan and Claypool Publishers.

Herring S. and Kapidzic, S. (2015). Teens, Gender, and Self-Presentation in Social Media, In J.D.Wright (ed.), International encyclopedia of social and behavioral sciences, Oxford: Elsevier.

Kahn, J.H., Tobin, R.M., Massey, A.E., Anderson, J.A. (2007). Measuring emotional expression with the Linguistic Inquiry and Word Count. The American Journal of Psychology, 263-286.

Kapidzic, S., \& Herring, S. C. (2014). Race, gender, and self-presentation in teen profile photographs. In J. D. Wright(eds.), International encyclopedia of social and behavioral sciences. Oxford: Elsevier

Kiss, J., 2013. Teenagers migrate from Facebook as parents send them friend requests. The Guardian, December 27. http://www.theguardian.com/technology/2013/dec/27/facebookdead- and-buried-to-teens-research-finds (accessed 19.01.2016).

Krauss, R.M., Chiu, C.Y. (2007). Language and Social Behavior. In: Gilbert, D., Fiske, S., Lindsey, G. (eds.) Handbook of Social Psychology, 2, 41-88. McGraw-Hill, Boston

Lenhart, A. (2012). Teens and video. Pew Internet and American Life Project. http://pewinternet.org/Reports/2012/Teens-and-online-video/Findings.aspx?view=all

(accessed 20.1.16).

Liu, H. (2008). Social Network Profiles as Taste Performances. Journal of Computer-Mediated Communication, 13: 252-275.

Maynard, D.W., and Peräkylä, A. (2006). Language and social interaction. In: DeLamater, J. (ed.) Handbook of Social Psychology, 233-257.

Mphahlel, M.L: and Mashamaite, M. (2005). The impact of Short Message Service (SMS) language on language proficiency of learners and the SMS dictionaries. A challenge for Educators and lexicographers. IADIS International Conference Mobile Learning.

Parate, A. and Tripathi , N. (2015). Impact and usages of social media messenger WhatsApp in society with special reference to Raipur City, Media Matters, 4(1), 65-71

Park, G., Schwartz, H. A., Eichstaedt, J. C., Kern, M. L., Kosinski, M., Stillwell, D. J., \& Seligman, M. E. (2015). Automatic personality assessment through social media language. Journal of personality and social psychology, 108(6), 934. 
Pennebaker, J.W., Graybeal, A. (2001). Patterns of natural language use: Disclosure, personality, and social integration. Current Directions in Psychological Science 10: 90-93.

Pennebaker, J.W., Mehl, M.R., Niederhoffer, K.G (2003). Psychological aspects of natural language use: Our words, our selves. Annual Review of Psychology 54: 547-577

Prensky, M., 2001. Digital natives, digital immigrants. On the Horizon. 9(5), 1-6.

Rankin, S. L. (2010). The impact of text messaging language shortcuts on developmental students' formal writing skills. Unpublished thesis, Walden University. Available Online at: http://www.proquest.com/enUS/products/dissertations/individuals.html

Salem, A. (2013). The impact of technology (BBM and WhatsApp Applications) on English linguistics in Kuwait. International Journal of Applied Linguistics \& English Literature, 2(4), 64-69.

Schwartz, H. A., Eichstaedt, J. C., Kern, M. L., Dziurzynski, L., Ramones, S. M., Agrawal, M., .Ungar, L. H. (2013). Personality, gender, and age in the language of social media: The open vocabulary approach. PLOS ONE, 8, e73791.http://dx.doi.org/10.1371/journal.pone.0073791

Seidlhofer, Barbara. 2011. Understanding English as a lingua franca. Oxford: Oxford University Press.

Stidham, S (2014). What's on your mind? A generational comparison of language use on online social networking platforms. Unpublished $\mathrm{PhD}$ thesis.

Sweeny, S. M. (2010). Writing for the instant messaging and text messaging generation: Using new literacies to support writing instruction. Journal of Adolescent \& Adult Literacy, 54:121-130.

Tausczik, Y., and Pennebaker, J. W. (2010). The psychological meaning of words: LIWC and computerized text analysis methods. Journal of Language and Social Psychology, 29, 24-54. http://dx.doi.org/10.1177/ $0261927 X 09351676$

Thurlow, C., \& Brown A. (2003). Generation txt: The sociolinguistics of young people's text-messaging. Discourse Analysis Online, 1, 1-27.

Yarkoni, T. (2010). Personality in 100,000 words: A large-scale analysis of personality and word use among bloggers. Journal of Research in Personality, 44, 363-373. http://dx.doi.org/10.1016/j.jrp. 